\title{
Transport Properties of Concentrated Aqueous Sodium Dodecyl Sulfate Solutions in Polymer Membranes Derived from Cellulose Esters
}

\author{
Artur J . M. Valente, ${ }^{\dagger}$ Alexandre Ya. Polishchuk, ${ }^{\ddagger}$ Victor M. M. Lobo, ${ }^{*}{ }^{\dagger}$ and \\ Hugh D. Burrows ${ }^{\dagger}$ \\ Department of Chemistry, University of Coimbra, 3004-535 Coimbra, Portugal, and \\ Institute of Biochemical Physics, Russian Academy of Sciences, 4 Kosygin Street, \\ Moscow 117334, Russia
}

Received February 28, 2000. In Final Form: May 15, 2000

\begin{abstract}
Polymer membranes with differing degrees of hydrophilicity were prepared from mixtures of cellulose acetate butyrate and cellul ose acetate hydrogen phthalate. The degree of hydrophilicity was determined from measurements of water uptakeand the apparent water diffusion coefficient. Thetransport properties of sodium dodecyl sulfate through these membranes were studied by measuring permeability using the time-lag technique. The mutual differential diffusion coefficients of the surfactant are 1-2 orders of magnitudelower than in aqueous solution. The permeability and partiti on coefficients between theaqueous subphase and membranes were found to depend on the hydrophilicity of the polymer blend, but to be virtually independent of temperature. Possi bleapplications of these systems in surfactant purification are suggested.
\end{abstract}

\section{Introduction}

Interactions between polymers and surfactants are of considerable practical importance, and studies on polymer-surfactant systems have been extensively reviewed. ${ }^{1-5}$ Various model s have been presented for these interactions, ${ }^{3,6-9}$ which differ in their degree of sophistication. However, they can be considered in terms of two limiting cases, one where the interactions are strongly cooperative, and surfactant monomer binds tothe polymer, and a second limit where surfactant micelles retain their integrity to form discrete clusters (pearl-necklace model) along the polymer chain. The relevant model to beapplied depends strongly on the degree of hydrophilic character of the polymer.

Particular interest has been focused on theinteractions between ionic surfactants, such as sodium dodecyl sulfate (SDS) and cellulose derivatives. ${ }^{10-20}$ With the watersoluble ethyl (hydroxyethyl)cellulose (EHEC) these inter-

† University of Coimbra.

₹ Russian Academy of Sciences.

(1) Interactions of Surfactants with Polymers and Proteins; Goddard, E. D., Ananthapadmanabhan, K. P., Eds.; CRC Press: Boca Raton, FL, 1993.

(2) Polymer-Surfactant Systems; Kwak, J . C. T., Ed.; Marcel Dekker: New York, 1998

(3) J önsson, B.; Lindman, B.; Holmberg, K.; Kronberg, B. Surfactants and Polymers in Aqueous Solution; Wiley: New York, 1998.

(4) Tanakari, R.; Meadows, J.; Phillips, G. O.; Williams, P. A Carbohydr. Polym. 1990, 12, 443.

(5) Brackman, J . C.; Engberts, J . B. F. N. Chem. Soc. Rev. 1993, 22, $85-92$.

(6) DeGennes, P. C. J . Phys. Chem. 1990, 94, 8407-8413.

(7) Evans, D. F.; Wennerström, H. TheCol loi dal Domain; VCH: New York, 1994, Chapter 7.

(8) Tanaka, F. Macromolecules 1998, 31, 384-393.

(9) Semenov, A. N.; Rubinstein, M. Macromol ecules 1998, 31, 13731385.

(10) Karlström, G.; Carlsson, A.; Lindman, B. J . Phys. Chem. 1990, 94, 5005-5015.

(11) Lindman, B.; Tochi, J .; Carlsson, A. In Cellulosics: Chemical, Biochemical and Medical Aspects; Kennedy, J. F., Phillips, G. O., Williams, P. A.. Eds.; Ellis Horwood: Chichester, 1993; pp 319-324.

(12) Kameka, N.; Burgaud, I.; Zana, R.; Lindman, B.J . Phys. Chem. 1994, 98, 6785-6789.

(13) Nyström, B.; Lindman, B. Macromol ecules 1995, 28, 967-974. actions lead to the formation of gel phases under certain conditions. ${ }^{13,15-18}$ These have a number of important practical applications. The surfactant-polymer interactions have been studied by various physical techniques, including cloud point measurements, ${ }^{10}$ gel filtration, ${ }^{14}$ electrical conductivity, ${ }^{12}$ timeresolved fluorescence quenching, ${ }^{12}$ rheology measurements, ${ }^{13,16,17}$ dynamic light scattering, ${ }^{13}$ nuclear magnetic resonance (NMR) self-diffusion, ${ }^{15}$ vibrational spectroscopy, ${ }^{18}$ and use of surfactantsel ective el ectrodes. ${ }^{19}$ The results indicate that there is a strong temperature-dependent interaction between SDS and EHEC, both below and above the conditions for gel formation. The surfactant critical micelle concentration (cmc) decreases in the presence of the polymer, and at low temperatures above the $\mathrm{cmc}$ small surfactant micellar aggregates form within the polymer domain. ${ }^{12}$ These appear toinvolvemainly binding of thesulfateheadgroups to the side chains of the polymer. ${ }^{18}$ As the temperature increases more specific surfactant binding to the polymer occurs. ${ }^{12,15}$ This may be associated with interactions between the surfactant headgroup and glucose rings on the cellulose ether chain, in addition to interactions with polymer-bound water molecules. ${ }^{18}$ Although some details of theseinteractions remain to beclarified, a fairly detailed picture is now available for surfactant interactions with this water-soluble cellul ose derivative. In contrast, rather less is known about interactions with SDS and waterinsol uble cellulose derivatives, although these are likely to be important in many areas, including textile $\mathrm{e}^{21}$ and

(14) Bloor, D.; Wan-Yunus, W. M. Z.; Wan-Badhi, W.A-; Li, Y.; Holzwarth, J . F.; Wyn-J ones, E. Langmuir 1995, 11, 3395-3400.

(15) Walderhaug, H.; Nyström, B.; Hansen, F .; Lindman, B.J . Phys. Chem. 1995, 99, 4672-4676.

(16) Nyström, B.; Kjoniksen, A.-L.; Lindman, B. Langmuir 1996, 12, 3233-3240.

(17) Kjoniksen, A.-L.; Nyström, B.; Lindman, B. Macromolecules 1998, 31, 1852-1858.

(18) Ostrovski, D.; Kjoniksen, A.-L.; Nyström, B.; Torell, L. M. Macromolecules 1999, 32, 1534-1540.

(19) Ghoreishi, S. M.; Li, Y.; Bloor, D. M.; Warr, J .; Wyn-J ones, E. Langmuir 1999, 15, 4380-4387.

(20) Tanaka, R.; Meadows, j .; Williams, P. A.; Phillips, G. O. Macromolecules 1992, 25, 1304-1310. 
Table 1. Composition of Membranes Prepared in $\mathbf{1 0} \%$ (w/v) THFa

\begin{tabular}{cccc}
\hline polymer blend & CAB fraction/wt \% & CAHP fraction/wt \% & $\mathrm{pH}^{\mathrm{b}}$ \\
\hline I & 100 & 0 & 6.239 \\
II & 33.3 & 66.7 & 3.781 \\
III & 14.3 & 85.7 & 3.594
\end{tabular}

a $\mathrm{THF}=$ tetrahydrofuran; $\mathrm{CAB}=$ cellulose acetate butyrate; $\mathrm{CAHP}=$ celluloseacetatehydrogen phthalate. ${ }^{\mathrm{b}} \mathrm{pH}$ values of water $(80 \mathrm{~mL}$, initial pH 6.315) after 1 week of contact with membranes (approximately $20-40 \mathrm{mg}$ ).

paper $^{22}$ processing, and separation science. ${ }^{23}$ Although quantitativestudies have been reported on theinteractions of SDS with latex particles, ${ }^{24}$ we are not aware of any detailed results on the interactions of SDS with films of cellulose derivatives.

We have previously reported the application of our method, originally developed for calculating mutual differential diffusion coefficients of el ectrolytes in aqueous solution ${ }^{25-27}$ from el ectrochemical conductivity measure ments, to the study of diffusion of electrolytes in polymer membranes. ${ }^{28-31}$ These measurements are extended to a study of the diffusion of ioni csurfactants in polymer films, and we report the diffusion of the surfactant SDS in cellul oseester membranes of differing hydrophilicity. The materials were prepared from mixtures of the relatively hydrophobic polymer cellulose acetate butyrate and the more hydrophilic cellulose acetate hydrogen phthalate, and their degree of hydrophilicity was quantified.

\section{Experimental Section}

Reagents. Experiments on SDS permeability through cellulose-derivative membranes were performed using aqueous solutions $\left(0.11-0.44 \mathrm{~mol} \mathrm{dm}^{-3}\right)$, obtained by dissolving the corresponding amount of solid SDS (Merck, pro analysis) in distilled water. SDS standard solutions were prepared by dilution of the above concentrated solution and used to study the dependence of conductivity on SDS concentration.

Preparation and Characterization of Membranes. Table 1 shows the composition of threedifferent polymer blends derived from celluloseacetate butyrate (CAB) (containing 17\% butyrate) and cellulose acetate hydrogen phthalate (CAHP).

The two polymers were initially dissolved in tetrahydrofuran (Merck) (concentration 10\% w/v) and stirred for $24 \mathrm{~h}$. Subsequently, thepolymer blend of required composition was prepared by mixing appropriate quantities of each solution and stirring for a further $24 \mathrm{~h}$. The sol ution was then deposited on a flat glass support and spread out with a specially designed apparatus to produce a membrane of uniform thickness (approximately 0.33 $\mathrm{mm}$ ). After complete evaporation of the solvent at room tem-

(21) Isarin, J .-C.; Kaasjager, A. D. J .; Holweg, R. B. M. Text. Res. J 1995, 65, 61-69.

(22) Upton, B. H.; Krisnagopalan, G. A.; Abubakr, S. TAPPI J . 1999, 82, 104-114.

(23) Pelizzetti, E.; Maurino, V.; Minero, C.; Pramauro, E. In The Structure, Dynamics and Equilibrium Propertiesof Colloidal Systems; Bloor, D. M., Wyn-J ones, E., Eds.; Kluwer: Dordrecht, TheNetherlands, 1990; pp 325-353.

(24) Stubbs, J . M.; Durant, Y. G.; Sundberg, D. C. Langmuir 1999, $15,3250-3255$

(25) Agar, J. N.; Lobo, V. M. M. J . Chem. Soc., Faraday Trans. 1975 $71,1659-1666$

(26) Lobo, V. M. M.; Valente, A. J . M. Port. Electrochim. Acta 1996 $14,133-137$

(27) Lobo, V. M. M.; Ribeiro, A. C. F.; Verissimo, L. M. P. J . Mol . Liq. 1998, 78, 139-149.

(28) Lobo, V. M. M.; Valente, A.J . M. Int. J . Polym. Mater. 1994, 25, $139-142$.

(29) Lobo, V. M. M.; Valente, A.J . M. Polym. Degrad. Stab. 1994, 44 $147-150$.

(30) Polishchuk, A. Ya.; Zaikov, G. E.; Zimina, L. A.; Lobo, V. M. M.; Valente, A. J. M. Polym. Compos. 1994, 2, 247-251.

(31) Lobo, V. M. M.; Murtinho, D. B.; Gil, M. H.; Garcia, F. P.; Valente A. J . M. Int. J . Polym. Mater. 1996, 32, 221-233.

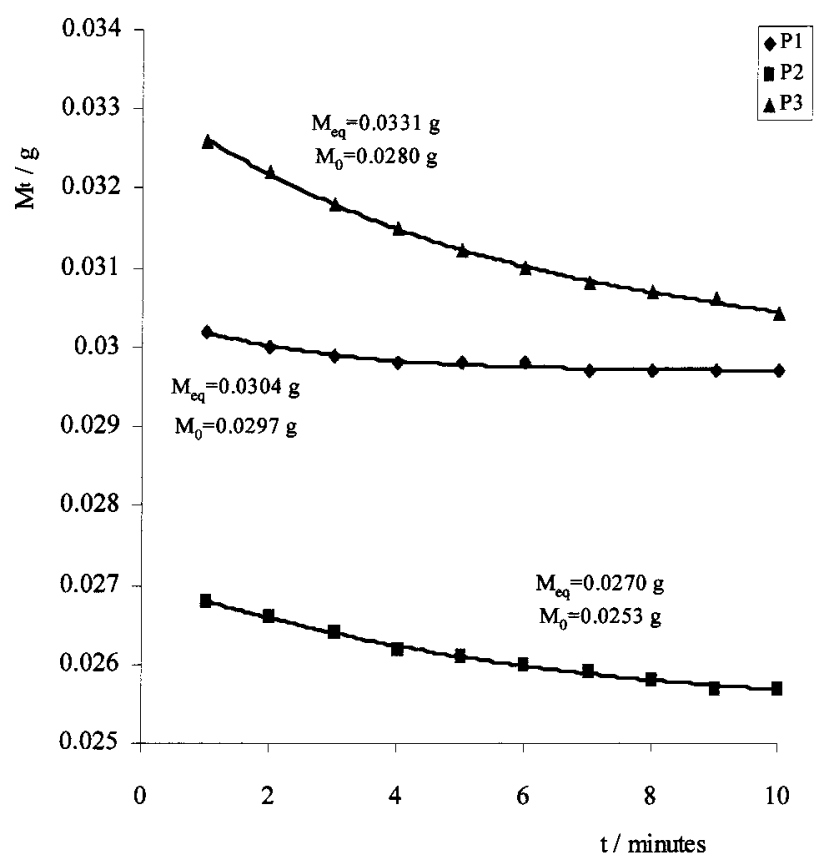

Figure 1. Water desorption for the three different cellulose ester membranes studied at $25^{\circ} \mathrm{C}$.

perature, the membrane was removed from the glass support with the help of water.

Thehydrophilic character of themembranes was characterized by measuring the degree of hydrophilicity $\left(H_{p}\right.$, taken as the percentage weight gain on water sorption) and theapparent water diffusion coefficient ( $D_{w}$, calculated from water desor ption curves), Three samples of each membrane were placed in a desiccator containing a saturated solution of $\mathrm{CuSO}_{4} \cdot 5 \mathrm{H}_{2} \mathrm{O}$, which provides a relative humidity of $98 \%$. Each specimen remained inside the desiccator until thesampleweight reached an equilibrium value, $M_{\text {eq }}$ (normally 2 days as found by a control experiment). Then, water desorption to constant weight, $M_{0}$, was carried out inside a vacuum oven at $100{ }^{\circ} \mathrm{C}$. After any drops of water were wiped off, the weight of the membrane, $\left(\mathrm{M}_{\mathrm{t}}\right)$ was measured at selected times using an analytical balance (Sartorius Analytical, \pm 0.1 $\mathrm{mg})$.

$M_{e q}$ and $D_{w}$ werecomputed using a Fickian approach tofitting the water desorption curves (Figure 1 )

$$
M_{t} / M_{\text {eq }}=1-4\left(D_{w} t / \pi l^{2}\right)^{0.5}
$$

following which $\mathrm{H}_{\mathrm{p}}$ was cal culated as

$$
H_{p}=\left(M_{\text {eq }}-M_{o}\right) 100 / M_{0}
$$

Thepolymer CAHP contains an ionizablecarboxylicacid group. To assess the degree of dissociation of this acid in contact with water, samples of the three membranes $(20-40 \mathrm{mg})$ were kept in contact with $80 \mathrm{~mL}$ of water at $25^{\circ} \mathrm{C}$, and the $\mathrm{pH}$ of theaqueous phase was measured after a week, using a combined $\mathrm{pH}$ el ectrode and a Radiometer PHM $240 \mathrm{pH}$ meter, with a $\mathrm{pH}$ resolution of 0.001 . These values are also presented in Table 1. While "pH" within a polymer membrane is a dubious concept, the fact that thevalues for the supernatant phases in contact with membranes P2 and P 3 are bel ow typical values for model aromatic carboxylic acids, such as 2-acetoxybenzoic acid $\left(\mathrm{pK}_{\mathrm{a}}=4.57\right), 32$ strongly suggests that the carboxylic acid group is predominantly protonated under these conditions.

Permeability Measurements. SDS transport properties were analyzed by measuring the permeability of this surfactant through polymer membranes using the timelag technique. ${ }^{33}$

(32) Albert, A.; Serjeant, E. P. The Determination of I onization Constants, 2nd ed.; Chapman and Hall: London, 1971; p 85.

(33) Faucher, J . A.; Goddard, E. D. J . Colloid I nterfaceSci. 1978, 65, 444-450. 
Table 2. Degree of Hydrophilicity $\mathrm{H}_{\mathrm{P}}$, and Apparent Water Diffusion Coefficients, $D_{w}$, in Cellulose Derivatives at $25^{\circ} \mathrm{C}$

\begin{tabular}{ccc}
\hline polymer blend & $\mathrm{H}_{\mathrm{P}}( \pm \mathrm{s}) / \%$ & $\mathrm{D}_{\mathrm{w}}( \pm \mathrm{s}) /\left(10^{-11} \mathrm{~m}^{2} \mathrm{~s}^{-1}\right)$ \\
\hline P1 & $3.4(0.5)$ & $8.3(0.3)$ \\
$\mathrm{P} 2$ & $8.3(0.4)$ & $2.9(0.3)$ \\
P3 & $20(1)$ & $1.2(0.2)$
\end{tabular}

Since this technique has been described in detail elsewhere, ${ }^{34}$ we will only specify details relating to our experimental conditions. The device consisted of two $250 \mathrm{~mL}$ cells filled with surfactant solution $(A)$ and water $(B)$, respectively. These two cells were connected by two $7 \mathrm{~mm}$ radius horizontal tubes. The polymer membrane was sealed, with silicone, between thesetwo tubes. Control experiments were performed to ensure that there is nosiliconein thepermeation area, and that themass transport occurs at the polymer-solution interface only. To prevent any contribution from the hydrostatic pressure ${ }^{34}$ to the mass flux, cell A was filled with $180 \mathrm{~mL}$ of SDS solution, while $170 \mathrm{~mL}$ of water was used in theother cell. Themembranes were immersed in water for at least 3 days prior to the experiments. The change in the SDS concentration in cell B was determined during the permeability experiment by measuring theel ectrical conductivity in this cell by a YSI 3200 instrument. The conductivity instrument was calibrated (i.e., the dependence of the conductivity on the SDS concentration measured) prior to each experiment using at least five freshly prepared standard solutions of SDS with different concentrations at least an order of magnitude lower than the $\mathrm{cmc}$. The same conditions were used for calibration and permeability experiments. Constant temperature $\left( \pm 0.1^{\circ} \mathrm{C}\right)$ was maintained throughout theexperiments by immersing thesystem in a thermostat bath (Velp Sientifica Multistirrer 6). Solutions in both cells were stirred at ca. 200 rpm to decrease the Nernst layer in the membrane-solution interface and to increase the reproducibility of the conductivity sensor. Data were recorded during the first $10 \mathrm{~h}$ for each experiment, with the time being sufficient to secure a steady-state flux of surfactant, but such that its concentration in cell $B$ was always well below the $\mathrm{cmc}$ $(\leq 10 \%)$.

Time-Lag Method. The permeability of SDS through the polymeric membranes can be described in terms of Fickian diffusion 35

$$
\partial \mathrm{C} / \partial \mathrm{t}=\partial / \partial \mathbf{x}\left(\mathrm{D}_{\mathrm{F}} \partial \mathrm{C} / \partial \mathbf{x}\right)
$$

with the boundary and initial conditions $\mathrm{C}(0, \mathrm{t})=\mathrm{C}_{\mathrm{SDS}}, \mathrm{C}(\mathrm{l}, \mathrm{t})=$ 0 , (where $\mathrm{C}_{S D S}$ is the concentration of the surfactant in the membrane) and $C(x, 0)=0$, resulting in the simple formulas for calculation of the permeability $(P)$ and apparent diffusion coefficient $\left(D_{F}\right)$

$$
\begin{gathered}
P_{S}=J I / C_{S D S} \\
D_{F}=I^{2} / 6 \theta
\end{gathered}
$$

where I is the thickness of the polymeric membrane, measured after each experiment at $25^{\circ} \mathrm{C}$ using a Helias micrometer $( \pm 0.01$ $\mathrm{mm}), \mathrm{J}$ is a steady-state flux through the membrane, $\theta$ is its

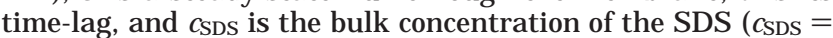
$\mathrm{KC}_{\text {SDS }} ; \mathrm{K}$ is the partition coefficient).

However, when the surfactant concentration in solution is above the cmc, the diffusion of the surfactant is complicated by theaggregation equilibrium between singl esurfactant mol ecules and micel les. In this case, which is the case for our experimental conditions, the flux of the surfactant through a polymer membrane depends on the concentrations of counterions, monomers, and micelles. 36,37

The formation and destruction of micelles are much faster processes than surfactant diffusion. ${ }^{36}$ Since at concentrations

(34) Tokita, M. J pn. J . Appl. Phys. 1995, 34, 2418-2422.

(35) Daynes, H. A. Proc. R. Soc. London 1920, 97A, 286-307.

(36) Weinheimer, R. M.; Evans, D. F.; Cussler, E. L. J . Colloid Interface Sci. 1981, 80, 357-363.

(37) Evans, D. F.; Mukherjee, S.; Mitchell, D. J .; Ninham, B. H. J . Colloid Interface Sci. 1983, 93, 184-204.

\begin{tabular}{|c|c|c|c|}
\hline \multirow[b]{2}{*}{$\begin{array}{l}\text { polymer } \\
\text { blend }\end{array}$} & \multirow[b]{2}{*}[SDS]{$/ M$} & \multirow{2}{*}{$\begin{array}{c}\mathrm{T}=25^{\circ} \mathrm{C} \\
\mathrm{D}_{\mathrm{m}}( \pm \mathrm{s}) / \\
\left(10^{-12} \mathrm{~m}^{2} \mathrm{~s}^{-1}\right)\end{array}$} & \multirow{2}{*}{$\begin{array}{c}\mathrm{T}=40^{\circ} \mathrm{C} \\
\mathrm{D}_{\mathrm{m}}( \pm \mathrm{s}) / \\
\left(10^{-12} \mathrm{~m}^{2} \mathrm{~s}^{-1}\right.\end{array}$} \\
\hline & & & \\
\hline \multirow[t]{4}{*}{$\mathrm{P} 1$} & 0.11 & $1.8(0.3)$ & $9.4(0.8)$ \\
\hline & 0.22 & $3.0(0.3)$ & $14(1)$ \\
\hline & 0.33 & $1.3(0.2)$ & $15(2)$ \\
\hline & 0.44 & $2.2(0.2)$ & $17(5)$ \\
\hline \multirow[t]{4}{*}{ P2 } & 0.11 & $1.8(0.6)$ & $5.6(0.4)$ \\
\hline & 0.22 & $1.4(0.2)$ & $8.8(0.2)$ \\
\hline & 0.33 & $5.5(0.9)$ & 19(1) \\
\hline & 0.44 & $8.4(1.3)$ & $21(5)$ \\
\hline \multirow{4}{*}{ P3 } & 0.11 & $7.0(0.8)$ & $5.3(0.8)$ \\
\hline & 0.22 & $14(1)$ & $4.0(0.3)$ \\
\hline & 0.33 & $15(5)$ & $4.0(0.5)$ \\
\hline & 0.44 & $12(2)$ & $8.4(0.4)$ \\
\hline
\end{tabular}

Table 3. Diffusion Coefficients, $D_{m}$, of SDS Monomers in Polymer Blends Derived from Cellulose at 25 and $40{ }^{\circ} \mathrm{C}$

abovethecmctheconcentration of surfactant present as micelles is usually higher than that of free monomer, the diffusion of surfactants is normally micelle controlled. ${ }^{38} \mathrm{H}$ owever, this is not the case for the polymer membranes, since the amount of water inside the polymers and the morphological structure and free volume of the membranes do not allow high molecular weight species, such as micelles, to contribute to the diffusion of the surfactant. Although the membranes P2 and P3 are not completely transparent, possibly indicating somemicrocrystalline zones, ${ }^{39,40}$ the sol vent evaporation technique used to form these films normally yields membranes with relatively low porosity, which depends on thechemical nature of the polymer. ${ }^{41}$ Scanning electron microscopy, thermal analysis, and high-resolution ${ }^{13} \mathrm{C}$ $\mathrm{CP} / \mathrm{MAS}$ nud ear magneticresonancespectral studies on cellul ose ester membranes prepared in the same way show that all those films may havezones with different degrees of crystallinity, and that while the surface presents pores and rough zones, the bulk of thefilm does not show any large pores. ${ }^{40}$ Therefore, we assume that the diffusing species permeating the polymer membranes arethesurfactant monomers. Wemay consequently assumethat the apparent Fickian diffusion coefficient is that due to the monomer $\left(D_{\mathrm{F}}=D_{m}\right)$. These assumptions mean that, as long as the SDS concentration in cell $\mathrm{A}$ is above the $\mathrm{cmc}$, the monomer concentration on this side of the polymer membrane remains constant $\left(\mathrm{C}(0, \mathrm{t})=[\mathrm{SDS}]_{\mathrm{cmc}}\right)$ due to the monomer/micelle equilibrium. Therefore eq 6 can be rewritten as

$$
P_{\mathrm{s}}=\mathrm{J} \mathrm{I} /[\mathrm{SDS}]_{\mathrm{cmc}}
$$

The critical micelle concentrations for SDS used in eq 6, were $8.16 \times 10^{-3}$ and $8.60 \times 10^{-3} \mathrm{~mol} \mathrm{dm}^{-3}$ at 25 and $40{ }^{\circ} \mathrm{C}$, respectively. ${ }^{42}$ It is al so reasonableto assumethat the counterion (sodium ion) diffuses with the dodecyl sulfate according to the electroneutrality principle. 43

The partition coefficient between the membrane and solvent, $K$, was finally calculated as P/D.

\section{Results and Discussion}

Table2 shows thewater uptake, $\mathrm{H}_{\mathrm{p}}$, and water diffusion coefficients, $D_{w}$ in three different polymeric membranes. Thesecan berelated directly tothedegree of hydrophilicity of the membranes, and polymer blends P 1 and P 2 can be characterized as "moderately hydrophilic", while P3 is classified as "hydrophilic". ${ }^{44}$ This allows an analysis of

(38) Cussler, E. L. Diffusion; Cambridge University: Cambridge, 1984; pp 164-165.

(39) Doyle, S.; Pethrick, R. A.; Harris, R. K.; Lane, J . M.; Packer, K J .; Heatley, F. Polymer 1986, 27, 19-24.

(40) Nunes, T.; Burrows, H. D.; Bastos, M.; Feio, G.; Gil, M. H. Polymer 1995, 36, 479-485.

(41) Piedade, A. P.; Guthrie, J. T.; Kazlauciunas, A.; Gil, M. H Cellulose 1995, 2, 243-263.

(42) Flockart, B. D. J . Colloid Sci. 1961, 16, 484-492.

(43) Mills, R. J . Electroanal. Chem. 1965, 9, 57-69.

(44) Zaikov, G. E.; Iordanskii, A. L.; Markin, V. S. Diffusion of Electrolytes in Polymers; VSP: The Netherlands, Utrecht, 1988. 
Table 4. Permeability, $P_{m}$, and Partition Coefficients, $K$, of SDS Monomers in Polymer Blends Derived from Cellulose at 25 and $40{ }^{\circ} \mathrm{C}$

\begin{tabular}{|c|c|c|c|c|c|}
\hline \multirow{2}{*}{$\begin{array}{l}\text { polymer } \\
\text { blend }\end{array}$} & \multirow[b]{2}{*}[SDS]{$/ M$} & \multicolumn{2}{|c|}{$\mathrm{T}=25^{\circ} \mathrm{C}$} & \multicolumn{2}{|c|}{$\mathrm{T}=40^{\circ} \mathrm{C}$} \\
\hline & & $\mathrm{P}_{\mathrm{m}}( \pm \mathrm{s}) / \mathrm{m}^{2} \mathrm{~s}^{-1}$ & K & $\mathrm{P}_{\mathrm{m}}( \pm \mathrm{s}) / \mathrm{m}^{2} \mathrm{~s}^{-1}$ & K \\
\hline \multirow[t]{4}{*}{$\mathrm{P} 1$} & 0.11 & $0.3(0.06) \times 10^{-17}$ & $1.7 \times 10^{-6}$ & $1.7(0.4) \times 10^{-17}$ & $1.8 \times 10^{-6}$ \\
\hline & 0.22 & $1.3(0.8) \times 10^{-17}$ & $4.3 \times 10^{-6}$ & $1.5(0.3) \times 10^{-17}$ & $1.1 \times 10^{-6}$ \\
\hline & 0.33 & $1.7(1.0) \times 10^{-17}$ & $13 \times 10^{-6}$ & $3.6(0.9) \times 10^{-17}$ & $2.4 \times 10^{-6}$ \\
\hline & 0.44 & $2.2(0.3) \times 10^{-17}$ & $10 \times 10^{-6}$ & $2.1(0.3) \times 10^{-17}$ & $1.2 \times 10^{-6}$ \\
\hline \multirow[t]{4}{*}{$\mathrm{P} 2$} & 0.11 & $8.6(0.7) \times 10^{-18}$ & $4.8 \times 10^{-6}$ & $3.1(0.3) \times 10^{-14}$ & $0.55 \times 10^{-2}$ \\
\hline & 0.22 & $5.9(0.0) \times 10^{-18}$ & $4.2 \times 10^{-6}$ & $9.7(0.1) \times 10^{-14}$ & $1.1 \times 10^{-2}$ \\
\hline & 0.33 & $10(4) \times 10^{-18}$ & $1.8 \times 10^{-6}$ & $19(8) \times 10^{-14}$ & $1 \times 10^{-2}$ \\
\hline & 0.44 & $13(0) \times 10^{-18}$ & $1.5 \times 10^{-6}$ & $30(10) \times 10^{-14}$ & $1.4 \times 10^{-2}$ \\
\hline \multirow[t]{4}{*}{ P3 } & 0.11 & $0.73(0.11) \times 10^{-13}$ & $1 \times 10^{-2}$ & $0.72(0.09) \times 10^{-13}$ & $1.4 \times 10^{-2}$ \\
\hline & 0.22 & $1.7(1.3) \times 10^{-13}$ & $1.2 \times 10^{-2}$ & $1.7(1.2) \times 10^{-13}$ & $4.3 \times 10^{-2}$ \\
\hline & 0.33 & $3.6(0.5) \times 10^{-13}$ & $2.4 \times 10^{-2}$ & $3.4(0.5) \times 10^{-13}$ & $8.5 \times 10^{-2}$ \\
\hline & 0.44 & $7.5(0.1) \times 10^{-13}$ & $6.3 \times 10^{-2}$ & $4.5(1.7) \times 10^{-13}$ & $5.4 \times 10^{-2}$ \\
\hline
\end{tabular}

the potential selectivity of these membranes toward the diffusion of concentrated SDS solutions $(0.1-0.44 \mathrm{~mol}$ $\left.\mathrm{dm}^{-3}\right)$. These values confirm that addition of cellulose acetate hydrogen phthalate increases membrane hydrophilicity. Another contributing factor to the hydrophilic character of the blends may be phase separation of the two pol ymers, which cl early occurs in P3. However, lower apparent values of water diffusion coefficient in more hydrophilic materials can also be explained by the formation of the water clusters due to a high local water concentration increase combined with these phase separation effects. This feature of thewater diffusion coefficient is reported as typical for cellulose derivatives. ${ }^{44,45}$ I nformation on the interaction of water with cellulose ester membranes has also come from NMR spectral ${ }^{46}$ and relaxation time ${ }^{47}$ measurements, and shows the presence of both polymer-bound and bulk water.

Diffusion coefficients of SDS were measured in the polymer membranes at 25 and $40{ }^{\circ} \mathrm{C}$. The diffusion coefficients of SDS monomers ( $D_{m}$ as in Table 3$)$ are 1-2 orders of magnitude lower than those reported for an aqueous solution. ${ }^{48}$ This shows that the pol ymeric matrix plays an important role in mass transport by diffusion, and acts essentially as an obstacletothediffusion process, increasing the effective diffusion path of the SDS.

Given the fairly large standard deviations inherent in these measurements, it can be seen that, except for blend P2 at $40^{\circ} \mathrm{C}$, the diffusion coefficients are nearly constant for each system, supporting our assumption that the monomer species aretheonly significant diffusing species insidemembranes. Thislow precision in thedetermination of integral diffusion coefficients appears to be a common feature of these systems, and may be a consequence of threeeffects, differences between the polymer membrane samples, an additional flux due to convection, and the formation of Nernst layers, which may all affect the final flux. These will, hence, affect the values determined for the diffusion and permeability coefficients. Thesurfactant behavior in $\mathrm{P} 2$ at $40{ }^{\circ} \mathrm{C}$ requires further consideration. Possibly, the increase in $D_{m}$ with SDS concentration in this case may be related to structural changes within the blend due to the temper ature increase. Such a change in SDS diffusion behavior is accompanied in P 2 by al terations in other parameters (solubility and permeability).

The lower diffusion coefficient observed at higher temperature in the blend P3 can be explained by an

(45) Polishchuk, A. Ya.; Zaikov, G. E. Multicomponent Transport in Polymer Systems for Controlled Release; Gordon Breach Science Publishers: Amsterdam, 1997.

(46) Buchanan, C. M.; Edgar, K. J :; Wilson, A. K. Macromolecules 1991, 24, 3060-3064

(47) Froix, M. F.; Nelson, R. Macromolecules 1975, 8, 726-730.

(48) Deng, Z.; Lu, H.; Leaist, D. G. J . Chem. Eng. Data 1996, 41, 214-217. increase in the quantity of SDS within the membrane (Table 4), which may result in aggregation due to more intense monomer-monomer or monomer-polymer interactions, as has been reported for SDS and EHEC in aqueous solution ${ }^{49,50}$ interactions. The higher concentration of micelles and/or SDS aggregates should reduce measurableapparent diffusion coefficients. ${ }^{51}$ In addition, it is possible that changes in the conformation of the polymers occur on increasing temperature. On the basis of a model for the phase behavior of aqueous solutions of poly(ethylene oxide), 52 it has been suggested that conformational changes are important in the temperature dependence of SDS-cellulose ether interactions in solution. ${ }^{10}$

Table 4 shows the permeability, $\mathrm{P}_{\mathrm{m}}$, and partition $\mathrm{K}$, coefficients of the monomers of SDS at 25 and $40{ }^{\circ} \mathrm{C}$.

It is not possible to measure SDS permeability at surfactant concentrations below $0.1 \mathrm{~mol} \mathrm{dm}^{-3}$, and some uncertainty exists in the measurements at the lowest concentrations. However, from theseresults it can beseen that thesolubility and permeability of SDS and, therefore, the selectivity of the membrane to surfactant can be affected in two ways. Homopolymer P1 is characterized by having a lower SDS solubility in the membrane at higher temperature, with the effect being morepronounced at the higher SDS concentrations. When this is combined with an increase of the diffusion coefficient, it results in a surfactant permeability which is nearly independent of temperature. SDS permeability through the blend P 3 is al so unaffected by temperature. However, the solubility and diffusion dependencies on temperature in this mate rial are exactly the opposite of those in P1. I ncreasing the temperature increases further the hydrophilicity of P3, leading to an increase in the solubility of the surfactant. An increase in thepermeability coefficients is alsoobserved with an increase of the hydrophilicity of the polymer, as measured by the increased water uptake, $\mathrm{H}_{\mathrm{p}}$. In addition to the hydrophilicity of the polymer, specific interactions increase between SDS and the membranes, such as those observed with EHEC in aqueous solution. ${ }^{12,15,18,19}$ Our measurements do not provide any quantitative information on this. However, $\mathrm{pH}$ measurements (see the $\mathrm{Ex}$ perimental Section) favor an assumption that the acidic groups in CAHP are all likely to be protonated, such that anion-anion repulsion is not likely to be important, while specific inter actions with either the cellul ose backbone or the ester side groups will depend strongly on the access of the SDS, and hence on membrane hydrophilicity.

(49) Singh, S. K.; Nilsson, S. I. Colloid I nterfaceSci. 1999, 213, 133

(50) Lindell, K.; Cabane, B. Langmuir 1998, 14, 6361-6370.

(51) Crank, J . TheMathemati cs of Diffusi on; Oxford University Press: Oxford, 1956.

(52) Karlström, G. J . Phys. Chem. 1985, 89, 4962-4964. 
In general, SDS permeability increases with its concentration, showing that although micelles do not permeate the membrane, they do produce further pressure on the solution-membrane interface. This pressure is an extra factor contributing tothetransport process, resulting in an increase in the monomer permeability coefficient. It also shows the difficulties in measurements of SDS permeability at concentrations below $0.1 \mathrm{~mol} \mathrm{dm}^{-3}$.

\section{Concluding Remarks}

Experimental data on the mass transport of concentrated aqueous solutions of SDS in cellulose ester based membranes show a high selectivity of these materials to SDS, which depends on both the water uptake capacity of the membraneand thetemperature. A blend of thetwo cellulose esters (P2) was prepared, which showed very interesting behavior in terms of SDS permeability, solubility, and diffusion coefficients, which suggests that the macromolecular structure of this blend is very sensitive to the temperature. This formulation could be a starting material for the development of matrixes with very broad commercial applications in terms of surfactant separation and purification. Work is in progress to extend these studies to surfactants with different chain lengths and charges.

Acknowledgment. We are grateful to Professor $M$. da G. Miguel for her valuable comments on polymersurfactant interactions. Financial support from PRAXIS XXI (Project 2/2.1/QUI/411/94) is gratefully acknowledged. 